\title{
The influence of starter cultures on the lactic acid bacteria microbiota of Petrovac sausage
}

\author{
Bojana Milićević $^{1 *}$, Vladimir Tomović ${ }^{2}$, Bojana Danilović ${ }^{1}$ and Dragiša Savić1 \\ ${ }^{1}$ Faculty of Technology, University of Nis, Leskovac, Serbia; ${ }^{2}$ Faculty of Technology, University of Novi Sad, Novi Sad, \\ Serbia
}

*Corresponding Author: Bojana Milićević, Faculty of Technology, University of Nis, Leskovac, Serbia, Email: bojanamilicevic@rocketmail.com

Received: 11 June 2020; Accepted: 18 February 2021; Published: 6 April 2021

(c) 2021 Codon Publications

OPEN ACCESS (c) (i) (우요

PAPER

\begin{abstract}
Petrovac sausage (Petrovská klobása) is a high-quality fermented dry sausage produced traditionally in the municipality of Bački Petrovac (Vojvodina, Serbia). The product is characterised by specific and recognised texture, aroma and colour, produced without additives or preservatives. Lactic acid bacteria (LAB) microbiota plays an important role in production of the sausage. The aim of the paper is to monitor the changes in LAB during the production of Petrovac sausage. Samples of sausages were prepared without and with the addition of starter culture Staphylococcus xylosus as well as combined starter culture Lactiplantibacillus plantarum and S. xylosus, and produced at two different temperature ranges. A total number of 495 strains were isolated from 33 samples of Petrovac sausage during 120 days of production process. Characterisation of the isolates was performed by phenotypic tests, while molecular identification of the representative strains was done by $16 \mathrm{~S}$ ribosomal DNA sequencing. The total number of LAB was about $8 \log$ (Colony Forming Unit (CFU))/g in all samples, while the number of staphylococci was about $4 \log \mathrm{CFU} / \mathrm{g}$. Molecular identification confirmed that all isolates belonged to the following species: Levilactobacillus brevis, Leuconostoc mesenteroides, Lactiplantibacillus plantarum and Pediococcus pentosaceus. Lactobacilli and Leuconostoc spp. dominate the total LAB strains, while P. pentosaceus was isolated at the lowest frequency.
\end{abstract}

Keywords: fermented sausages, lactic acid bacteria, Petrovac sausage, $16 \mathrm{~S}$ rDNA sequencing

\section{Introduction}

The production of fermented sausages correlate with the diversity of microbiota present in meat batter as well as those added in the form of starter culture (Cocconcelli and Fontana, 2008; Toldra, 2002). Starter cultures contribute to the functional properties of fermented products and play a major role in the improvement of organoleptic, technological, nutritional and health characteristics of fermented sausages (Laranjo et al., 2017). Different types of microorganisms (Lactic Acid Bacteria [LAB], staphylococci and micrococci, mould, and yeasts) can be used for autochthonous and commercial starter cultures in the production of fermented sausages (Casaburi et al., 2008; Kovacevic et al., 2010). Combination of Lactobacillus spp. and Staphylococcus spp. used as starter cultures in the sausages production can contribute to the pleasant aroma of sausages and they possess antimicrobial properties against unwanted microorganisms and pathogen microbiota (Hosseini and Pilevar, 2017). Owing to acidification, lipolysis, and proteolysis, and production and development of volatile aroma compounds, LAB microbiota (Lactobacillus sakei, Lactiplantibacillus pentosus, Lactobacillus curvatus, Lactiplantibacillus plantarum, Lacticaseibacillus paracasei, Levilactobacillus brevis etc.) play an essential role of a starter culture in meat fermentation (Ammor and Mayo, 2007; Kumar et al., 2017). Production of lactic and acetic acid reduces $\mathrm{pH}$ of the meat batter resulting in the formation of characteristic sausage aroma and consistency. The acidification process plays an important role in the inhibition and inactivation of pathogenic microorganisms contributing to the prolonged shelf life and safety of fermented sausages (Leistner, 1995; Martinovic and Veskovic-Moracanin., 
2006). LAB species can produce bacteriocins as antimicrobial products of fermentation. L. sakei, L. curvatus, L. plantarum and L. paracasei, which are often used as starter cultures, contribute to the safety and stability of fermented sausages because of strong antibacterial activity against Escherichia coli and Listeria monocytogenes (Pidcock et al., 2002; Veskovic-Moracanin, 2010). In addition to the safety of product, some strains of lactobacilli used as starter cultures (L. sakei, L. curvatus and L. plantarum) promote the degradation of peroxide (Martinovic and Veskovic-Moracanin., 2006).

Gram-positive cocci used as starter cultures (Staphylococcus carnosus, Staphylococcus xylosus and Micrococcus varians) play an important role in the reduction of nitrates and nitrites, decomposition of peroxides, lipolysis stabilisation and development of texture (Skocińska et al., 2016). S. carnosus and S. xylosus as starter cultures contribute to the development of desirable colour and aroma in fermented sausages. Owing to antioxidant properties, growth on optimal salt concentrations and growth on optimal pH, S. carnosus and S. simulans are often used as starters in fermented sausages (Casaburi et al., 2005).

Dry-fermented sausages represent the result of physical, chemical, biochemical, microbiological and sensory changes that occur during the ripening of meat batter (Hammes et al., 2008). Petrovac sausage (Petrovská klobása) is a traditional dry-fermented product made in Bački Petrovac (Vojvodina, Serbia). As a high-quality fermented product with appropriate texture, aroma and colour, it is produced without additives or preservatives, and protected by Protected Denomination of Origin (PDO) at the national level (Ikonic et al., 2015; Petrovic et al., 2007). Petrovac sausage can be produced without adding starter cultures (Danilovic et al., 2018). The traditional production excludes the addition of starter cultures (Ikonic et al., 2016; Jokanovic et al., 2017, 2010).

The aim of this work was to monitor the changes in LAB microbiota in the samples of Petrovac sausage (Petrovská klobása) prepared without and with the addition of starter culture S. xylosus and combined starter cultures $L$. plantarum and S. xylosus and produced under controlled conditions in two different temperature ranges. For this purpose, isolation, characterisation and identification of LAB microbiota were performed.

\section{Materials and methods}

\section{Fermented sausage technology and sampling procedure}

Fermented sausages were produced according to the traditional recipe in the Agro-Industrial Complex (AIC)
'Bačka Topola' (Vojvodina, Serbia). Meat batter was made of minced pork (85\%) and solid back fat tissue (15\%) with addition of the following ingredients (w/w): red hot pepper $(2.5 \%)$, salt $(1.8 \%)$, garlic $(0.2 \%)$, caraway seeds $(0.2 \%)$ and sucrose $(0.1 \%)$. The meat batter was divided into three equal parts: control sausages $(\mathrm{H})$ (without addition of starter), sausages (I) (with the addition of combined starter cultures of S. xylosus and L. plantarum) and sausages (J) (with the addition of starter culture of S. xylosus). The initial number of starter cultures in meat batter was the same for LAB and coagulase-negative cocci (CNC) (4.5-5.0 log (CFU)/g). Autochthonous starter cultures were previously isolated from traditionally produced Petrovac sausage (Danilovic, 2012). The mixture was stuffed into artificial collagen casings. Smoking, drying and ripening of the sausages were carried out under controlled conditions in the ripening chamber at the temperature range of $14-16^{\circ} \mathrm{C}(\operatorname{tag} 1)$ and $\sim 10^{\circ} \mathrm{C}(\operatorname{tag} 2)$. All experiments were performed in triplicate. Samples were collected after 0 (meat batter), 6, 15, 60, 90 and 120 days of production.

\section{Isolation and enumeration of bacteria}

For microbiological analysis, $10 \mathrm{~g}$ of each sausage sample was aseptically homogenised in $90 \mathrm{~mL}$ of sterile saline peptone water $(8 \mathrm{~g} / \mathrm{L} \mathrm{NaCl}+1 \mathrm{~g} / \mathrm{L}$ peptone) (Urso et al., 2006). The enumeration of microorganisms was performed in triplicate by the successive serial dilution method and represented as the mean value. Dilutions were prepared and plated on nutrition agar (NA, Torlak, Belgrade, Serbia), de Man, Rogosa and Sharpe (MRS) agar (Torlak, Belgrade, Serbia) and Mannitol Salt Agar (MSA) plates for determining the total number of mesophilic bacteria, LAB and staphylococci, respectively. After the incubation of plates $\left(48 \mathrm{~h}, 30^{\circ} \mathrm{C}\right)$ and enumeration, randomly selected colonies from MRS agar plates were streaked to new MRS agar plates for purification.

\section{Phenotypic identification and characterisation of $L A B$ isolates}

Basic characterisation of the isolates was performed through Gram reaction, cell morphology and catalase test with $\mathrm{H}_{2} \mathrm{O}_{2}(30 \% \mathrm{v} / \mathrm{v})$. Gram-positive and catalase-negative isolates were subjected to the following physiological tests: $\mathrm{CO}_{2}$ production, arginine and esculin hydrolysis, bacterial growth on MRS agar plates at different temperatures $\left(15^{\circ} \mathrm{C}\right.$ and $\left.45^{\circ} \mathrm{C}\right)$ for $72 \mathrm{~h}$, bacterial growth on MRS agar plates supplemented with $\mathrm{NaCl}(4 \%$, $6.5 \%$ and $8 \%$ ) for $72 \mathrm{~h}$, bacterial growth on bile esculin agar, synthesis of exopolysaccharides and the synthesis of bacteriocines. 
Arginine hydrolysis was performed in arginine broth (g/L: tryptophan 5, L-arginine 3, glucose 0.5 and $\mathrm{K}_{2} \mathrm{HPO}_{4}$ 2), while esculin hydrolysis was performed in esculin broth (Torlak, Belgrade, Serbia). After incubation, a few drops of phenyl-red were added to the arginine broth (red colour indicates a positive reaction, and yellow colour a negative one), and a few drops of $2 \%$ $\mathrm{FeCl}_{3}$ solution to the esculin broth (a positive reaction is the appearance of a black precipitate). For preliminary identification of enterococci, isolates were grown on bile esculin agar (Rocheux's Medium, Himedia, Mubai, India). The appearance of black colonies indicate the presence of enterococci. Exopolysaccharide production was detected visually (appearance of mucous colonies) after incubation of isolates on a modified MRS medium supplemented with maltose, sucrose, galactose, fructose, lactose and glucose (Merck GmbH, Darmstadt, Germany) at a temperature of $30^{\circ} \mathrm{C}$ for $48 \mathrm{~h}$.

The bacteriocinogenic activity was performed using the agar well diffusion assay. Soft nutrition agar $(0.7 \% \mathrm{w} / \mathrm{v})$, containing indicator strain, was poured into plates with thin layer of MRS agar. After hardening of the medium, small diameter wells $(10 \mathrm{~mm})$ were made into plates. Into each well, aliquot $(50 \mu \mathrm{L})$ of the supernatant of overnight culture (16 h) was poured. Also, a crystal of pronase E was added close to the edge of the bacteriocin-containing well. The plates were incubated at $30^{\circ} \mathrm{C}$ for $24 \mathrm{~h}$. Appearance of a clear inhibition zone around the well was recorded as a positive signal for production of bacteriocin. For detecting bactericiongenic activity, Bacillus subtilis, Listeria monocytogenes and E. coli were used as pathogenic microorganisms. Production of bacteriocin against any of the analysed strains was stated as positive.

\section{Molecular identification of LAB isolates}

Isolation of the total genomic DNA as well as (GTG)5PCR fingerprinting was performed as described previously (Nikolic et al., 2008). For $16 \mathrm{~S}$ ribosomal DNA (rDNA) sequencing method, PCR amplifications with primers UNI 16SF (5'-GAG AGT TTG ATC CTG GC-3) and UNI 16SR (5'-AGG AGG TGA TCC AGC CG-3') were performed with a Taq DNA polymerase kit (Fermentas UAB, Vilnius, Lithuania). The amplification of the samples was performed through GeneAmp PCR system 2700 (Applied Biosystems) operated with the following parameters: the initial duration of DNA for $7 \mathrm{~min}$ at $95^{\circ} \mathrm{C}, 32$ cycles of denaturation of $1 \mathrm{~min}$ at $94^{\circ} \mathrm{C}$, polymerisation with a duration of $8 \mathrm{~min}$ at $65^{\circ} \mathrm{C}$, and the final extension of incomplete product with a duration of $16 \mathrm{~min}$ at $65^{\circ} \mathrm{C}$. Plasmide profiles were monitored on $1.5 \%(\mathrm{w} / \mathrm{v})$ agarose gel with ethidiumbromide at a constant voltage of $60 \mathrm{~V}$ (at $4^{\circ} \mathrm{C}$ for $20 \mathrm{~h}$ ) (Versalovic et al., 1994). Visualisation of PCR products was performed by applying CCD camera Biometra BDR2/5/6 (Bio Doc Analyze). Specific PCR products were analysed by electrophoresis on $1 \%$ agarose gel and purified using QIAquick PCR Purification KIT/250 (Qiagen, Hilden, Germany). Purified PCR amplicons were sequenced using Macrogen sequencing service in Seoul, South Korea. The results were compared with the data stored in the National Centre for Biotechnology Information (NCBI) gene databank using BLAST algorithm (www. ncbi.nlm.nih.gov/BLAST).

\section{Results and discussion}

Petrovac sausage is an indigenous fermented sausage produced of minced meat and spices without preservatives with specific and recognisable characteristics. The sausage fermentation process is greatly affected by the changes in the development and composition of LAB and staphylococci microbiota. In order to determine the changes in LAB microbiota during the production of Petrovac sausage with the addition of starter cultures, sausage samples were prepared without starter culture (sausages $\mathrm{H}$ ), with combined starter culture L. plantarum and S. xylosus (sausages I) and with starter culture S. xylosus (sausages J). Production of the sausages was performed under controlled conditions at a temperature range of $14-16^{\circ} \mathrm{C}(\operatorname{tag} 1)$ and $\sim 10^{\circ} \mathrm{C}(\operatorname{tag} 2)$.

During the production of Petrovac sausage, the change in the number of mesophilic bacteria was almost identical to the change in LAB regardless of using starters. In the sausages prepared without starter cultures (sausages $\mathrm{H}$ ), the number of initial LAB and aerobic mesophilic bacteria was about $5 \log \mathrm{CFU} / \mathrm{g}$, while the number of staphylococci ranged about $4 \log \mathrm{CFU} / \mathrm{g}$. The maximum value of LAB and aerobic mesophilic bacteria (8-9 log CFU/g) was reached after 15 days and it remained stable till the end of the production process. The number of staphylococci at the end of the process was lower and was about $3 \log$ $\mathrm{CFU} / \mathrm{g}$ (Figure $1 \mathrm{H})$. Similarly, in the sausages prepared with combined starter culture of S. xylosus and L. plantarum (sausages I), the initial number of LAB was almost identical to the initial number of aerobic mesophilic bacteria (about $5 \log \mathrm{CFU} / \mathrm{g}$ ). During the production of sausages I, similar changes in the number of both LAB and aerobic mesophilic bacteria were observed as in sausages $\mathrm{H}$. The number of staphylococci in sausages I was in the same range as in sausages prepared without starter cultures (3-4 log CFU/g) (Figure 1I). In sausages prepared with the addition of starter culture S. xylosus (sausages J), the number of staphylococci at the end of production was higher in all samples produced at $14-16^{\circ} \mathrm{C}$ (about $3 \log \mathrm{CFU} / \mathrm{g}$ ) than in the samples produced at $\sim 10^{\circ} \mathrm{C}$ (about $2 \log \mathrm{CFU} / \mathrm{g}$ ). Changes in the number of LAB and aerobic mesophilic bacteria were almost identical as in sausages I (Figure 1J). 
The number of LAB in sausages produced without starter culture $(\mathrm{H})$ during the first days of fermentation was in accordance with the results obtained for Tunisian dry-fermented sausage produced without starter culture (4.3 log CFU/g). However, the initial number of LAB in sausages I and J (about $5 \mathrm{log}$ CFU/g) was lower than the number of LAB obtained for Tunisian sausages produced with combined starter culture of S. xylosus and L. plantarum (7.3 log CFU/g) (Essid and Hassouna, 2013). The rapid increase in LAB during the first days of fermentation is also in accordance with the rapid increase in dry-fermented poultry sausages prepared without starter cultures $(8.3 \mathrm{CFU} / \mathrm{g})$, with starter culture of S. xylosus or L. plantarum $(8.9 \mathrm{CFU} / \mathrm{g})$ and mixed starter culture of S. xylosus and L. plantarum (8.8 CFU/g) (El Adabi et al., 2014). Also, the maximum level of number of LAB during the first 15 days (8-9 log $\mathrm{CFU} / \mathrm{g}$ ) was in accordance with the results obtained for Tunisian sausages produced with combined starter culture of S. xylosus and L. plantarum (8.1 log CFU/g) (Essid and Hassouna, 2013). Rapid increase in the total number of aerobic mesophilic bacteria in all samples during the first days of production process was in accordance with the results obtained for the samples of Petrovac sausages produced under traditional conditions (5-8.5 log $\mathrm{CFU} / \mathrm{g}$ ) and for the samples produced under controlled conditions (5-7 log CFU/g) (Danilovic et al., 2018). The total number of aerobic mesophilic bacteria was in

(H)

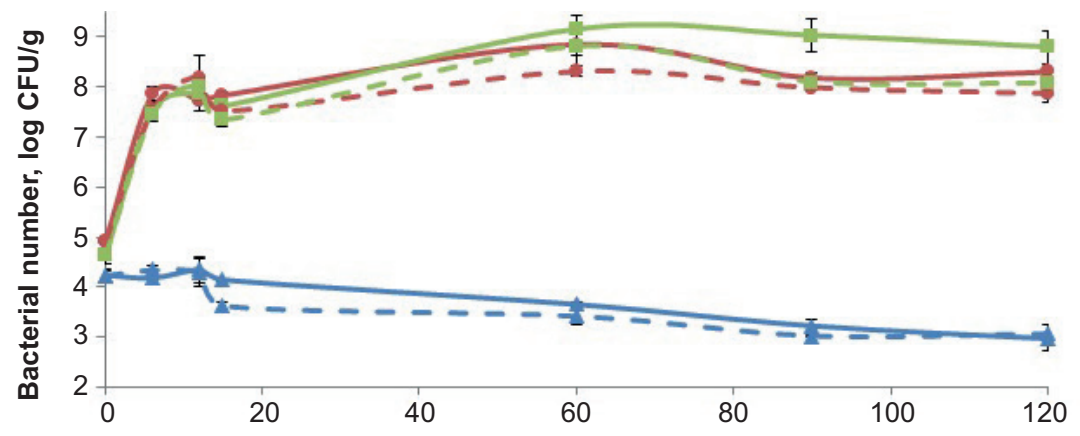

(I)

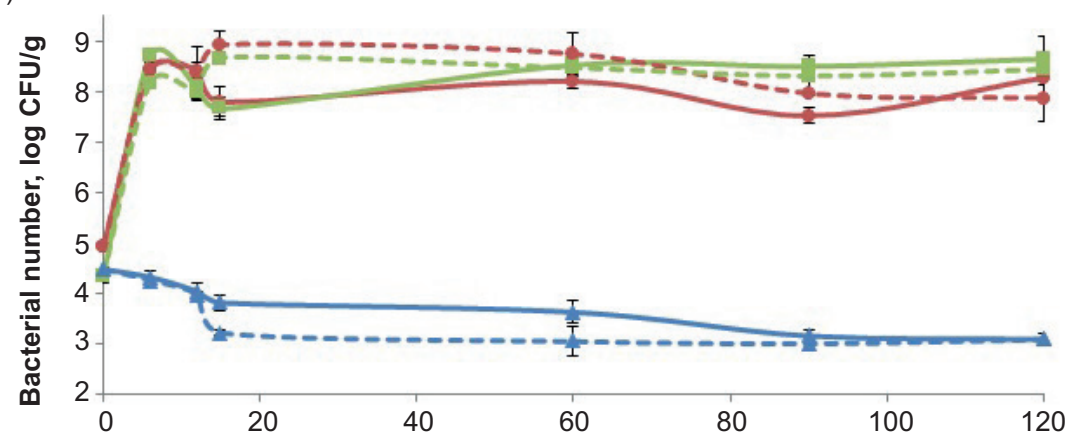

(J)

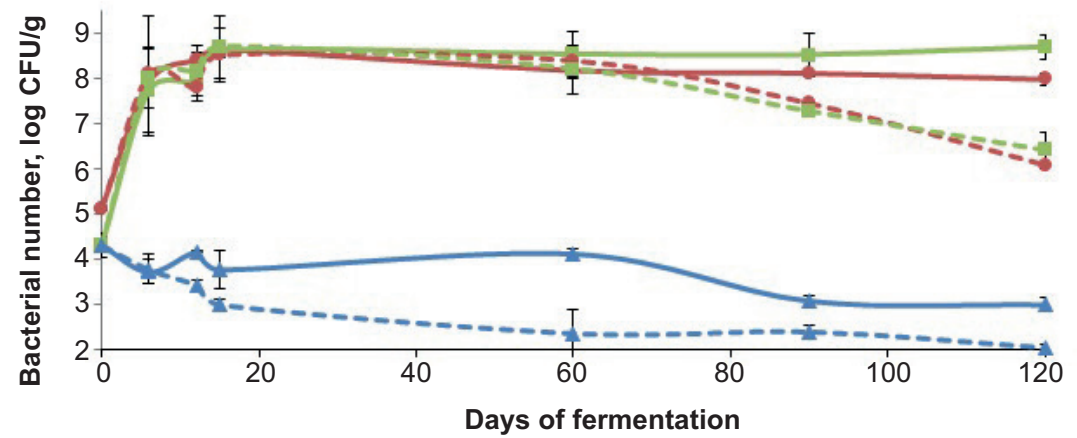

Figure 1. The number of aerobic mesophilic bacteria ( $\bullet$, red line), LAB ( $\boldsymbol{\square}$, green line) and staphylococci ( $\mathbf{\Delta}$, blue line) during the production of Petrovac sausages prepared without starter cultures $(\mathrm{H})$, with combined starter culture $\mathrm{S}$. xylosus and L. plantarum (I), and with S. xylosus (J) and produced at $14-16^{\circ} \mathrm{C}$ (full line) and $\sim 10^{\circ} \mathrm{C}$ (dashed line). Vertical error bars represent standard deviation. 
accordance with the results obtained for Petrovac sausages produced under traditional and controlled conditions (7-8 log CFU/g; Danilovic et al., 2018) and for the sausages produced from hot deboned meat (Danilovic et al., 2011). Results obtained for Petrovac sausages indicated that LAB microbiota, being the dominant microbiota during the production process, were in accordance with the results of Casaburi et al. (2008), Casquete et al. (2012) and Zdolec et al. (2008). Domination of LAB microbiota in Petrovac sausages was in accordance with the results obtained for Alheira-fermented sausage produced in Portugal (Albano et al., 2009), traditional Greek dry-fermented sausages (Ambrosiadis et al., 2004; Papamanoli et al., 2003), dry-fermented sausages produced with L. sakei (Bolumar et al., 2006) and Tunisian dry-fermented beef sausage produced with combined starter culture of S. xylosus and L. plantarum (Essid and Hassouna, 2013). The initial number of staphylococci in sausages $\mathrm{H}, \mathrm{I}$ and $\mathrm{J}$ (about $4 \log \mathrm{CFU} / \mathrm{g}$ ) was lower than the number of the same microbiota in Tunisian beef sausage produced without starter culture ( $5 \log \mathrm{CFU} / \mathrm{g}$ ) and with combined starter culture of S. xylosus and L. plantarum (7 log CFU/g) (Essid and Hassouna, 2013). The lower number of staphylococci at the end of production process was probably due to reduction in $\mathrm{pH}$ caused by lactobacilli (Johansson et al., 1994; Lizaso et al., 1999). Addition of starter culture had no effect on the total number of staphylococci. The higher number of staphylococci in the samples produced at higher temperature range $\left(14-16^{\circ} \mathrm{C}\right)$ than the number presented in samples produced at lower temperature $\left(\sim 10^{\circ} \mathrm{C}\right)$ was in accordance with the results obtained for Italian fermented sausages, where the growth of S. xylosus was better at higher temperatures (Fiorentini et al., 2010). Other results confirmed that increasing temperature from $10^{\circ} \mathrm{C}$ to $26^{\circ} \mathrm{C}$ increased growth of S. xylosus, S. carnosus and S. equorum, with strong synergy between temperature and $\mathrm{pH}$ (Søndergaard and Stahnke, 2002). The number of both aerobic mesophilic bacteria and LAB was identical regardless of the addition of starter cultures S. xylosus and $L$. plantarum. These results were in accordance with the results obtained for Tunisian dry-fermented sausages produced with the addition of starter cultures S. xylosus and L sakei (Najjari et al., 2020).

A total of 495 Gram-positive and catalase-negative strains were isolated from 33 samples during the production of Petrovac sausage. Phenotypic grouping of strains by cell morphological characteristics divided all isolates into five groups (Table 1). The identity of the isolate was confirmed by (GTG)5-PCR and 16S rDNA sequencing. The $16 \mathrm{~S}$ ribosomal RNA (rRNA) gene sequence analysis confirmed that all isolates belonged to L. brevis, L. mesenteroides, L. plantarum and P. pentosaceus species. DNA analyses of the PCR-amplified 16S rRNA gene fragments obtained from purified isolates during sausage production provided the fingerprints shown in Figure 2. The (GTG)5 fingerprints didn't show intraspecific biodiversity.

Gram-positive, catalase-negative and rod-shaped cells were classified as lactobacilli. Arginine-negative group of lactobacilli had the ability to grow well at $15^{\circ} \mathrm{C}$ and in the presence of $6 \%, 5 \%$ and $8 \%$ of $\mathrm{NaCl}$. This group didn't

Table 1. Characterisation of LAB isolated during the production of Petrovac sausage.

\begin{tabular}{|c|c|c|c|c|}
\hline Group & $\mathrm{I}$ & II & III & IV \\
\hline No. of isolates & 188 & 172 & 131 & 4 \\
\hline Cell morphology & rods & Rods & coccoid & cocci \\
\hline $\mathrm{CO}_{2}$ formation & - & - & + & - \\
\hline \multicolumn{5}{|l|}{ Growth at } \\
\hline $45^{\circ} \mathrm{C}$ & - & - & - & - \\
\hline $15^{\circ} \mathrm{C}$ & + & + & + & + \\
\hline \multicolumn{5}{|l|}{ Growth on $\mathrm{NaCl}$} \\
\hline $4 \%$ & - & - & & - \\
\hline $6.5 \%$ & + & + & + & + \\
\hline $8 \%$ & + & + & + & + \\
\hline Hydrolysis of arginine & - & - & - & - \\
\hline Hydrolysis of esculin & - & - & + & + \\
\hline Black colonies on bile esculin agar & - & - & - & - \\
\hline production of EPS from sucrose & - & + & + & - \\
\hline Production of bacteriocines & v & V & - & v \\
\hline Identified by $16 \mathrm{~S}$ rDNA gene sequencing & L. brevis & L. plantarum & L. mesenteroides & P. pentosaceus \\
\hline
\end{tabular}


$\begin{array}{lllllllll}1 & 2 & 3 & 4 & 5 & 6 & 7 & 8 & 9\end{array}$

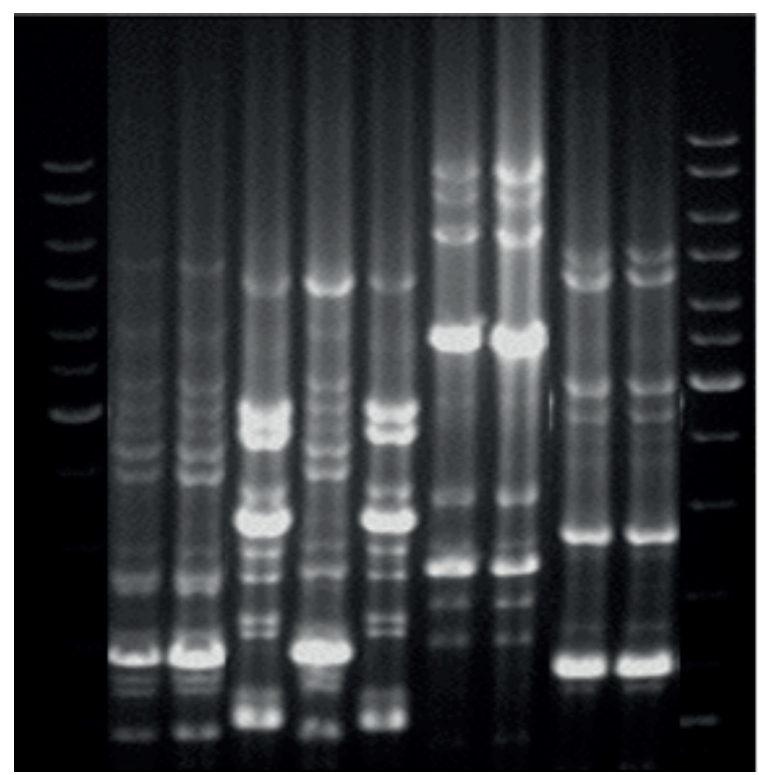

Figure 2. Reference PCR profiles of the amplified 16S rRNA gene of the isolates: $L$. brevis $(1,2,4), L$. plantarum $(3,5)$, $P$. pentosaceus $(6,7)$ and $L$. mesenteroides $(8,9)$.

produce $\mathrm{CO}_{2}$ and was not able to grow at $45^{\circ} \mathrm{C}$. On the basis of morphological characteristics, two groups of lactobacilli were observed. (GTG)5-PCR fingerprinting (Figure 2) confirmed that two groups belonged to L. brevis and L. plantarum. Some L. brevis and L. plantarum strains synthesised bacteriocines, which was in accordance to the data found in literature that these species could be active against $L$. monocytogenes (Tosukhowong et al., 2011). Also, nitrite-reduction capability is one of the most important characteristics of L. brevis (Paik and Lee, 2014). Additionally, L. plantarum leads to rapid decrease of $\mathrm{pH}$ in fermented sausages and contributes to the organoleptic properties of the fermented product (Heinz and Hautzinger, 2007).

The arginine-negative and esculin-positive isolates that produced $\mathrm{CO}_{2}$ from glucose and had the ability of forming slimy colonies on MRS agar plates with sucrose were identified by $16 \mathrm{~S}$ rDNA sequencing as L. mesenteroides. Leuconostoc spp. produce lactic acid, acetic acid, dextran, acetaldehyde, diacetyl, ethanol and other metabolites that contributes to the development of aroma and flavour in production of fermented sausages (Lee et al., 2006). As heterofermentative strains, Leuconostoc spp. produce $\mathrm{CO}_{2}$, which is considered as one of the main causes in forming holes in meat products; this property classifies them as undesirable microbiota (Ammor and Mayo, 2007). Leuconostoc spp. may synthesise spectra of bacteriocines (mesentericin Y105, produced by L. mesenteroides spp. mesenteroides; leucocin A-UAL 187, produced by L. gelidum; carnosin 44A, produced by
L. carnosum; and leuconocin S, produced by L. paramesenteroides) that exhibit strong microbial activity against Listeria spp (Stiles, 1994). The prevalence of Leuconostoc spp. in sausages is in correlation with the results obtained for Petrovac sausages produced from hot deboned meat (Danilovic et al, 2011) as well as for sausages ripened under the traditional and controlled conditions (Danilovic et al., 2018).

Only four isolates $(0.8 \%)$ were esculine-positive cocci. They all had the ability to grow at $15^{\circ} \mathrm{C}$ as well as on MRS agar plates with addition of $\mathrm{NaCl}(6 \%, 5 \%$ and $8 \%)$. Some of cocci produced bacteriocines (Table 1). Esculinepositive cocci, which formed tetrads, were identified by $16 \mathrm{~S}$ rDNA sequencing as $P$. pentosaceus (Figure 2). As a result of low catabolism of amino acids, pediococci don't play a major role in the formation of organoleptic properties in fermented sausages (Leroy et al., 2006). Among pediococci, $P$. acidilactici and $P$. pentosaceus were often isolated from European sausages (Albano et al. 2007; Kozachinski et al. 2008). P. acidilactici produced pediocin that inhibits the growth of food-borne pathogens L. monocytogenes and Clostridium perfringens in Spanish dry-fermented sausages (Nieto-Lozano et al., 2010). In addition, $P$. pentosaceus showed strong inhibitory effect against S. aureus (Erdogrul et al., 2002). P. pentosaceus and $P$. acidilactici are commonly used as starters in the United States in producing dry sausages (Rantsiou and Cocolin, 2006). Besides bacteriocines, some strains of pediococci produce EPS (Semjonovs and Zikmanis, 2008). The low frequency of isolation of pediococci is correlated with the results obtained for Bosnian Sudzuk, Alheira sausage and Croatian sausage (Albano et al., 2009; Kozachinski et al., 2008). In Petrovac sausages produced from hot deboned meat, pediococci were isolated at the highest percentage after ninth day of production process (Danilovic et al., 2011).

Total isolated LAB microbiota constituted L. brevis (37.9\%), L. plantarum (34.7\%), L. mesenteroides (26.4\%) and $P$. pentosaceus $(0.8 \%)$. Sausages prepared without starter cultures ( $\mathrm{H} 1$ and $\mathrm{H} 2$ ) were characterised by the prevalence of leuconostoc spp. during the first 15 days of fermentation regardless of temperature. Complete replacement of leuconostoc spp. was observed after 15 days and lactobacilli were the dominant microbiota. On the 60th day of production process, L. plantarum rapidly increased up to $80 \%$ in sausages $\mathrm{H} 1$, while in sausages $\mathrm{H} 2$, almost equal distribution of $L$. brevis and L. plantarum was detected. Later stages of production process were characterised by the prevalence of L. plantarum. P. pentosaceus was isolated only from sausages H2 in a 90-dayold sample with a representation of $1.4 \%$ (Figure 3 ). On the other hand, in sausages prepared with the addition of combined starter cultures of S. xylosus and L. plantarum (sausages I1 and I2), the highest percentage of 

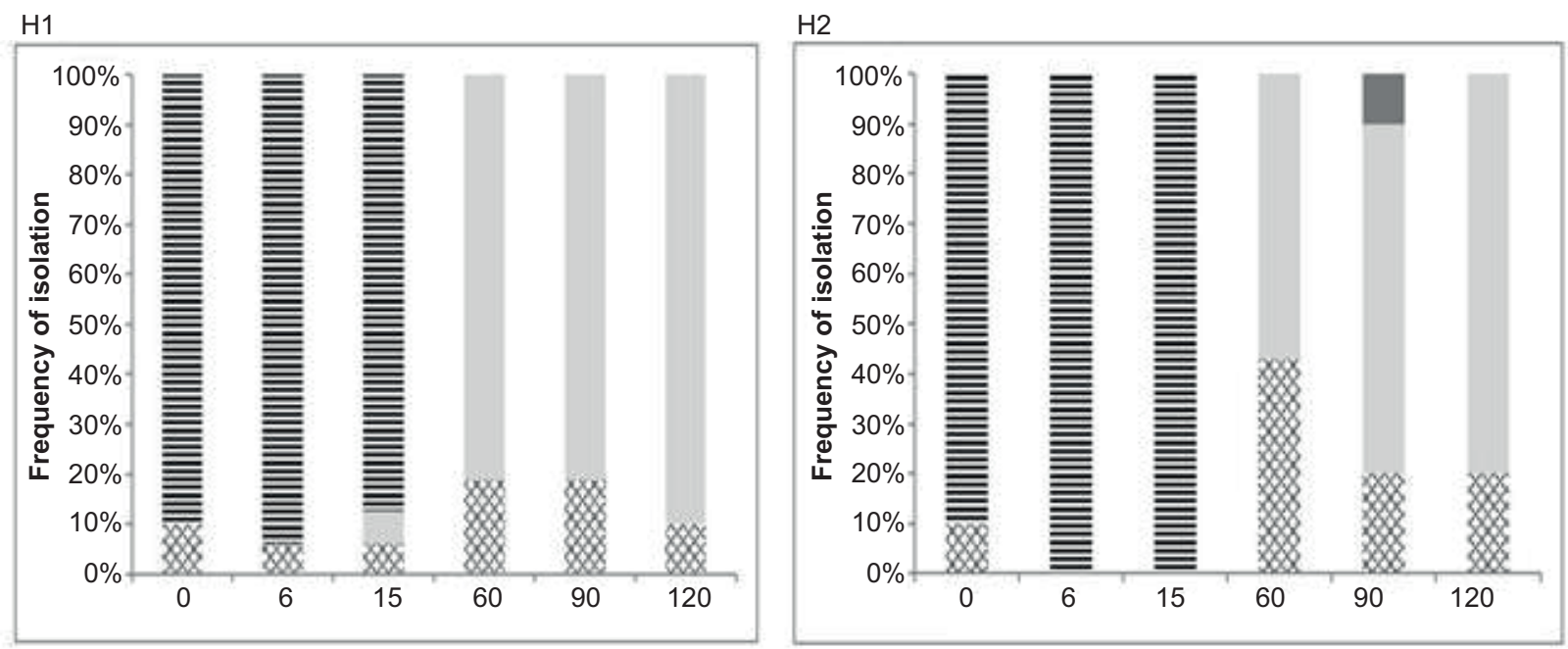

11

12
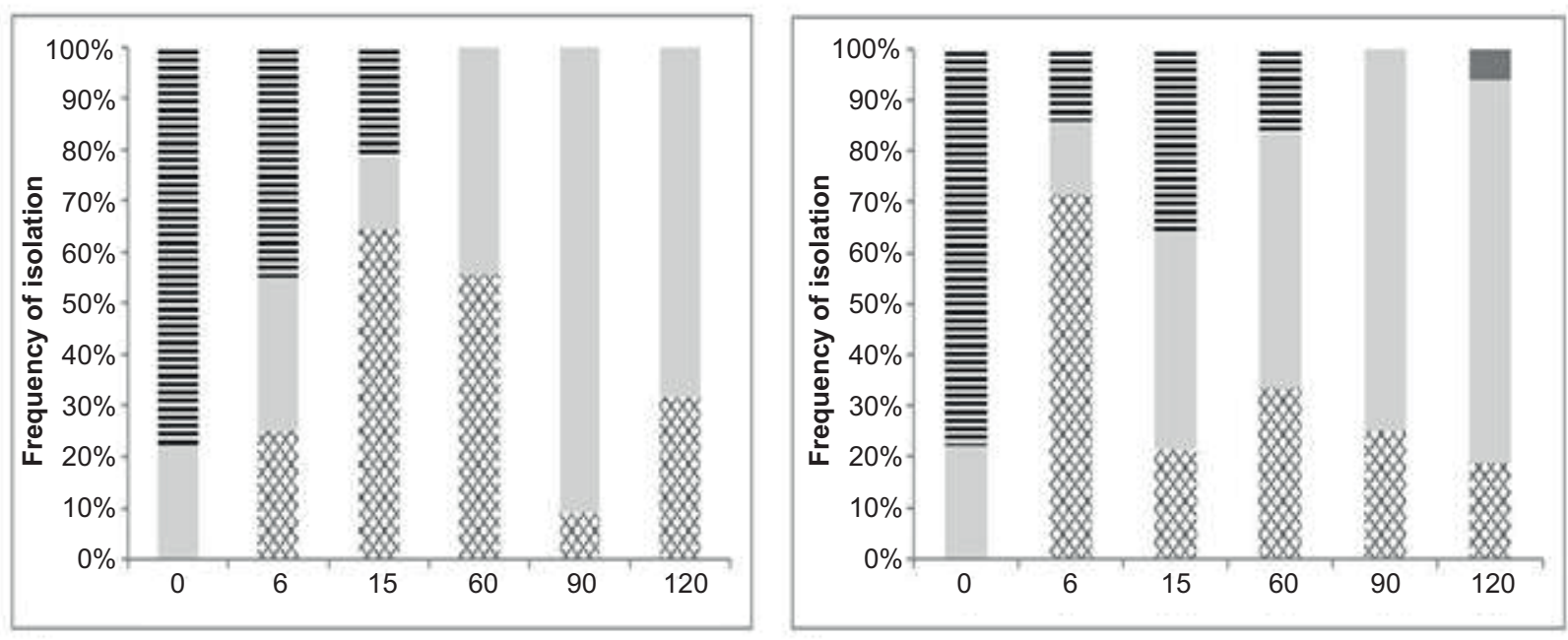

J1

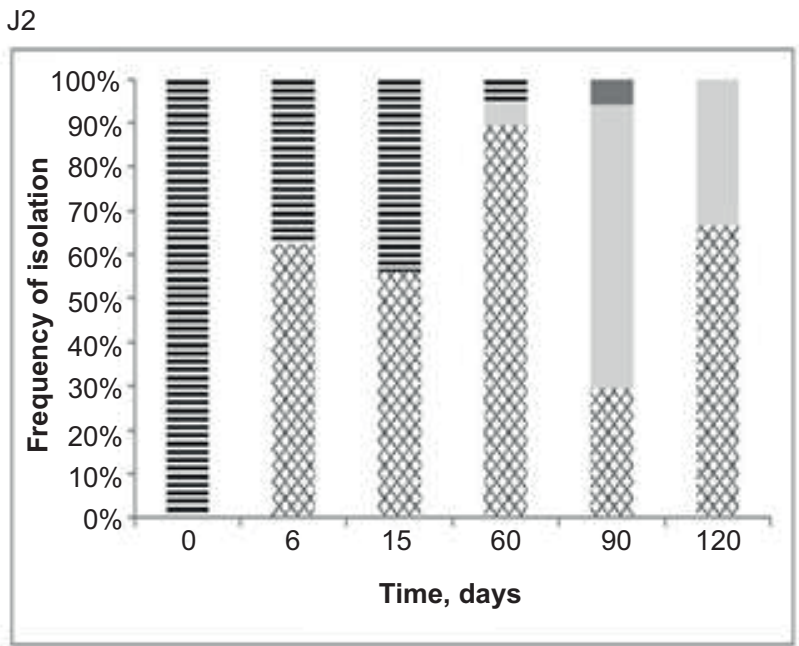

P.pentosaceus $\equiv$ L.mesenteroides L.plantarum L.brevis

Figure 3. Changes in microbial population during the production of Petrovac sausages prepared without starter cultures (sausages $\mathrm{H}$ ), with combined starter cultures of $S$. xylosus and L. plantarum (sausages I) and with starter culture of $S$. xylosus (sausages $\mathrm{J}$ ) produced at $14-16^{\circ} \mathrm{C}$ (samples with tag 1 ) and $\sim 10^{\circ} \mathrm{C}$ (samples with tag 2). 
leuconostoc strains was detected only in the meat batter. Leuconostoc spp. decreased immediately after preparation of sausage mixture but remained still up to the 15th day of production in sausages I1 and up to the 60th day of production in sausages I2. After this period, depletion of leuconostoc strain was observed and lactobacilli were the dominant microbiota (Figure 3). Pediococci were isolated only at the end of production process in sausages I2 with a share of $1 \%$. In sausages prepared with the addition of starter culture of S. xylosus (sausages J1 and J2), the domination of $L$. brevis was detected at all stages of production process except in the meat batter, where the full presence of L. mesenteroides (100\%) was detected. P. pentosaceus was detected on the 60th and 90th day of production in sausages J1 and J2, respectively. This increase in the content of lactobacilli was observed during production, with the presence of $100 \%$ lactobacilli in the sample after 120 days of production.

During the production of Petrovac sausage, the prevalence of $L$. mesenteroides was observed in the meat batter prepared with and without adding starter cultures. Also, L. mesenteroides strains were present during the early stages of fermentation process regardless of temperature. The high frequency of $L$. mesenteroides at the beginning of production process was in accordance with the results obtained for Serbian traditional fermented sausages Sremski kulen, Lemeski kulen (Vasilev et al., 2015) and Užička sausage (Borovic et al., 2017). On the contrary, these results were not in accordance with the results obtained for Italian fermented sausage (Comi et al., 2005; Urso et al., 2006), where low frequency of leuconostoc spp. was detected at the beginning of the production process. Regardless of the production conditions, in all sausages, lactobacilli were the dominant microbiota from 15 days till the end of production process. This is in accordance with the results obtained for Užička sausage (Borovic et al., 2017). Also, the high frequency of lactobacilli was presented in Sremski and Lemeški kulen (77.1 and 54.3\%, respectively). L. brevis was the most dominant lactobacilli species in these sausages (61.5\% and $57.9 \%$, respectively) (Vasilev et al., 2015). High frequency of L. brevis was in accordance with the results obtained for traditional fermented Užička sausage (Borovic et al., 2017); P. pentosaceus was isolated in the smallest percentage in the final stages of production, while in sausages ripened under traditional and controlled conditions, pediococci were present only in the meat batter $(1.7 \%$ of the total microbiota) (Danilovic et al., 2018). Pediococci were isolated in small percentage from Iberian dry-fermented sausagesSalcichon and Chorizo (Benito et al., 2008) and Italian fermented sausages-Salami (Bonomo et al., 2008). On the contrary, Pediococci were isolated at high frequency from the fermented sausages produced in the United States, where $P$. acidilactici and $P$. pentosaceus are commonly added as starter cultures (Anba-Mondoloni et al., 2015).

\section{Conclusion}

Petrovac sausage is an artisanal Serbian sausage appreciated for its sensory characteristics. In order to preserve the quality of the industrial production process, there is a need to understand the effect of starter cultures on the level of microbiota and composition. The results indicate that application of starter culture S. xylosus and combined starter culture S. xylosus and L. plantarum didn't influence the total number of LAB during process. On the other hand, temperature range of $14-16^{\circ} \mathrm{C}$ increased the number of staphylococci, compared with the application of $\sim 10^{\circ} \mathrm{C}$ temperature. Comparison of the effect of different starter cultures with the composition of microbiota resulted in the achievement of similar microbiota composition as for traditional sausages when combined starter culture was used. According to the results, combined starter culture of S. xylosus and L. plantarum could be the most promising solution for the production of Petrovac sausage, although further sensory analysis is required to be conducted.

\section{Acknowledgments}

This work was performed at the Faculty of Technology, University of Nis, Leskovac, Republic of Serbia, and funded by the Ministry of Education, Science and Technological Development of the Republic of Serbia, Grant No. 451-03-68/2021-14/200133.

\section{References}

Albano H., Todorov S.D., van Reenen C.A., Hogg T., Dicks L.M. and Teixeira P. 2007. Characterization of two bacteriocins produced by Pediococcus acidilactici isolated from "Alheira," a fermented sausage traditionally produced in Portugal. Int J Food Microbiol. 116(2):239-47. https://doi.org/10.1016/j. ijfoodmicro.2007.01.011

Albano H., Van Reenen C.A., Todorov S.D., Cruz D., Fraga L., Hogg T.,et al. 2009. Phenotypic and genetic heterogeneity of lactic acid bacteria isolated from "Alheira," a traditional fermented sausage produced in Portugal. Meat Sci. 82:387-398. https://doi. org/10.1016/j.meatsci.2009.02.009

Ambrosiadis J., Soultos N., Abrahim A. and Bloukas J.G. 2004. Physicochemical, microbiological and sensory attributes for the characterization of Greek traditional sausages. Meat Sci. 66:279-287. https://doi.org/10.1016/S0309-1740(03)00100-1

Ammor M.S. and Mayo B. 2007. Selection criteria for lactic acid bacteria to be used as functional starter cultures in dry sausage production: an Update. Meat Sci. 76:138-146. https://doi. org/10.1016/j.meatsci.2006.10.022

Anba-Mondoloni J., Champomier-Vergès M.C., Zagorec M., Leroy S., Dordet-Frisoni E., Planchon S. and Talon R. "The Genetics of Microbial Starters," in Handbook of Fermented Meat 
and Poultry: Second Edition, F. Toldrá, Ed., pp. 161-168, Wiley Blackwell, 2015. https://doi.org/10.1002/9781118522653.ch19

Benito M., Serradilla M.J., Ruiz-Moyano S., Martin A., PérezNevado F. and Cordoba G. 2008. Rapid differentiation of lactic acid bacteria from autochthonous fermentation of Iberian dry-fermented sausages. Meat Sci. 80:656-661. https://doi. org/10.1016/j.meatsci.2008.03.002

Bolumar T., Sanz Y., Flores M., Aristoy M.C., Toldra F. and Flores J. 2006. Sensory improvement of dry-fermented sausages by the addition of cell-free extracts from Debaryomyces hansenii and Lactobacillus sakei. Meat Sci. 72:457-466. https://doi. org/10.1016/j.meatsci.2005.08.010

Bonomo M.G., Ricciardi A., Zotta T., Parente E. and Salzano G. 2008. Molecular and technological characterization of lactic acid bacteria from traditional fermented sausages of Basilicata region (Southern Italy). Meat Sci. 80(4):1238-1248. https://doi. org/10.1016/j.meatsci.2008.05.032

Borovic B., Velebit B., Veskovic S., Lakicevic B. and Baltic T. 2017. The characterization of lactic acid bacteria isolated during the traditional production of Uzicka sausage. IOP Conference Series: Earth and Environmental Science, 59th International Meat Industry Conference MEATCON2017, Zlatibor, Serbia, Volume 85 (1), pp.0120179,1.10.2017-4.10.2017. https://doi. org/10.1088/1755-1315/85/1/012079

Casaburi A., Blaiotta G., Mauriello G. and Pepe O. 2005. Technological activities of Staphylococcus carnosus and Staphylococcus simulans strains isolated from fermented sausages. Meat Sci. 71(4):643-650. https://doi.org/10.1016/j. meatsci.2005.05.008

Casaburi A., Di Monacoa R., Cavellaa S., Toldrà F., Ercolini D. and Villani F. 2008. Proteolytic and lipolytic starter cultures and their effect on traditional fermented sausages ripening and sensory traits. Food Microbiol. 25:335-347. https://doi.org/10.1016/j. fm.2007.10.006

Casquete R., Benito M., Martin A., Ruiz-Moyano S., Aranda E. and Córdoba M.G. 2012. Microbiological quality of salchichón and chorizo, traditional Iberian dry-fermented sausages from two different industries, inoculated with autochthonous starter cultures. Food Control. 24(2):191-198. https://doi.org/10.1016/j. foodcont.2011.09.026

Cocconcelli P.S. and Fontana C. 2008. "Characteristics and Applications of Microbial Starters in Meat Fermentations," in Meat Biotechnology, F. Toldrá, Ed., pp. 129-148.

Comi G., Urso R., Iacumin I., Rantsiou K., Cattaneo P., Cantoni C., et al. 2005. Characterization of naturally fermented sausages produced in the north east of Italy. Meat Sci. 69:381-392. https://doi.org/10.1016/j.meatsci.2004.08.007

Danilovic B. 2012. Changes in the population of lactic acid bacteria during the production of petrovac sausage (Petrovská klobása). D. Sc. thesis, Faculty of Technology, University of Nis, Leskovac.

Danilovic B., Jokovic N., Petrovic Lj., Veljovic K., Tolinachki M. and Savic D. 2011. The characterisation of lactic acid bacteria during the fermentation of an artisan Serbian sausage (Petrovska Klobasa). Meat Sci. 88: 668-674. https://doi.org/10.1016/j. meatsci.2011.02.026
Danilovic B., Dzinic N., Milosavljevic N. and Savic D. 2018. Influence of processing conditions on the lactic acid bacteria population of a traditional sausage. Romanian Biotechnol Lett. 23(3):13661-13668.

El Adab S., Essid I. and Hassouna M. 2014. Effect of starter cultures on microbial and physicochemical parameters of a dry fermented poultry meat sausage. African J Biotechnol. 13(43):4155-4164. https://doi.org/10.5897/AJB2014.13874.

Erdogrul O.T., Cetin O. and Ergun O. 2002. A study on metabolic and antimicrobial activities of Pediococcus pentosaceus isolated from fermented sausages. Pak J Biol Sci. 5(5):594-596. https:// doi.org/10.3923/pjbs.2002.594.596

Essid I. and Hassouna M. 2013. Effect of inoculation of selected Staphylococcus xylosus and Lactiplantibacillus plantarum strains on biochemical, microbiological and textural characteristics of a Tunisian dry fermented sausage. Food Control 32(2):707-714. https://doi.org/10.1016/j.foodcont.2013.02.003

Fiorentini A.M., Sawitzki M.C., Bertol M., Cunha Junior A. and Sant'Anna E.S. 2010. Influence of a native strain of Staphylococcus xylosus on the microbiological, physicochemical and sensorial characteristics on milano salami type. Brazil Arch Biol Technol 53(4):961-974. https://doi.org/10.1590/ S1516-89132010000400027

Hammes W., Haller D. and Gänzle M. 2008. Fermented meat. In: Edward R. (Ted) Farnworth (ed.) Handbook of fermented functional foods, Taylor \& Francis, Boca Raton, pp. 291-321. https:// doi.org/10.1201/9780203009727

Heinz G. and Hautzinger P. 2007, June 1. Meat processing technology. For small-to medium scale producers. Food and Agriculture Organization of the United Nations (FAO), Regional Office for Asia and the Pacific, Bangkok. ISBN: 978-974-7946-99-4.

Hosseini H. and Pilevar Z. 2017. Effects of starter cultures on the properties of meat products: a review. Ann Res Rev Biol. 17(6):1-17. https://doi.org/10.9734/ARRB/2017/36330

Ikonic P., Jokanovic M., Petrovic Lj., Tasic T., Skaljac S., Sojic B., et al. 2016. Effect of starter culture addition and processing method on proteolysis and texture profile of traditional dry-fermented sausage Petrovská klobása. Int J Food Prop. 19:19241937. https://doi.org/10.1080/10942912.2015.1089280

Ikonic P., Jokanovic M., Tasic T., Skaljac S., Sojic B., Tomovic V., et al. 2015. The effect of different ripening conditions on proteolysis and texture of dry-fermented sausage Petrovská klobása. Procedia Food Sci. 5:97-100. https://doi.org/10.1016/j. profoo.2015.09.026

Johansson G., Berdague J.L., Larsson M., Tran N. and Borch E. 1994. Lipolysis, proteolysis and formation of volatile components during ripening of fermented sausage with Pediococcus pentosaceus and Staphylococcus xylosus as starter culture. Meat Sci. 38:203-218. https://doi.org/10.1016/0309-1740(94)90110-4

Jokanovic M., Ikonic P., Skaljac S., Tasic T., Tomovic V., Sojic B., et al 2017. Proteolysis and texture profile of traditional dry-fermented sausage as affected by primary processing method. Meat Technol. 58: 103-109.

Jokanovic M., Petrovic Lj., Ikonic P., Tomovic V., Dzinic N., Savatic S., et al 2010. Sensory properties of Petrovská klobása 
(dry-fermented sausage) ripened in traditional and industrial conditions. J Proc Energy Agricul. 14:153.

Kovacevic D., Mastanjevic K., Subaric D., Jerkovic I. and Marijanovic Z. 2010. Physico-chemical, colour and textural properties of Croatian traditional dry sausage (Slavonian kulen). Meat 12:270-276.

Kozachinski L., Drosinos E., Chaklovica F., Cocolin L., GasparikReichardt J. and Veskovic S. 2008. Investigation of microbial association of traditionally fermented sausages. Food Technol Biotechnol. 46:93-106.

Kumar P., Chatli M.K. and Verma A.K. 2017. Quality, functionality, and shelf life of fermented meat and meat products: a review. Crit Rev Food Sci. and Nutr. 57:2844-2856. https://doi.org/10.1 080/104.08398.2015.1074533

Laranjo M., Elias M. and Fraqueza M.J. 2017. The use of starter cultures in traditional meat products. J Food Quality 2017:1-18. https://doi.org/10.1155/2017/9546026

Lee J.Y., Kim C.J. and Kunz B. 2006. Identification of lactic acid bacteria isolated from kimchi and studies on their suitability for application as starter culture in the production of fermented sausages. Meat Sci. 72(3):437-445.https://doi.org/10.1016/j. meatsci.2005.08.013

Leistner L. 1995. Stable and safe fermented sausages worldwide. In: Campbell-Platt G. and Cook P.E. (eds.), Fermented meats. Blackie Academic \& Professional, Glasgow, Scotland, pp. 160175. https://doi.org/10.1007/978-1-4615-2163-1_7

Leroy F., Verluyten J. and De Vuyst L. 2006. Functional meat starter cultures for improved sausage fermentation. Int J Food Microbiol. 106(3):270-285. https://doi.org/10.1016/j. ijfoodmicro.2005.06.027

Lizaso G., Chasco J. and Beriain J. 1999. Microbiological and biochemical changes during ripening of salcichon, a Spanish dry cured sausage. Food Microbiol. 16:219-228. https://doi. org/10.1006/fmic.1998.0238

Martinovic A. and Veskovic-Moracanin S. 2006. Application of starter cultures in the meat industry. Meat Technol. 47(5-6):216-230.

Najjari A., Boumaiza M., Jaballah S., Boudabous A. and Ouzari H. 2020. Application of isolated Lactobacillus sakei and Staphylococcus xylosus strains as a probiotic starter culture during the industrial manufacture of Tunisian dry-fermented sausages. Food Sci. Nutr. 8:4172-4184. https://doi.org/10.1002/ fsn3.1711

Nieto-Lozano J.C., Reguera-Useros J.I., Peláez-Martínez M.D.C., Sacristán-Pérez-Minayo G., Gutiérrez-Fernández A.J. and Torre A.H.D. 2010. The effect of the pediocin PA-1 produced by Pediococcus acidilactici against Listeria monocytogenes and Clostridium perfringens in Spanish dry-fermented sausages and frankfurters. Food Control. 21:679-685. https://doi. org/10.1016/j.foodcont.2009.10.007

Nikolic M., Terzic-Vidojevic A., Jovcic B., Begovic J., Golic N. and Topisirovic L. 2008. Characterization of lactic acid bacteria isolated from Bukuljac, a homemade goat's milk cheese. Int J Food Microbiol. 122:162-170. https://doi.org/10.1016/j. ijfoodmicro.2007.11.075
Paik H.D. and Lee J.Y. 2014. Investigation of reduction and tolerance capability of lactic acid bacteria isolated from kimchi against nitrate and nitrite in fermented sausage condition. Meat Sci. 97:609-614. https://doi.org/10.1016/j.meatsci.2014.03.013

Papamanoli E., Tzanetakis N., Litopoulou-Tzanetaki E. and Kotzekidou P. 2003. Characterization of lactic acid bacteria isolated from a Greek dry-fermented sausage in respect of their technological and probiotic properties. Meat Sci. 65(2):859-867. https://doi.org/10.1016/S0309-1740(02)00292-9

Petrovic Lj., Dzinic N., Tomovic V., Ikonic P. and Tasic T. 2007. Code of practice - registered geographical indication Petrovská klobása. Decision No. 9652/06 G-03/06, Intellectual Property Office. Republic of Serbia.

Pidcock K., Heard G.M. and Henriksson A. 2002. Application of nontraditional meat starter cultures in production of Hungarian salami. Int J Food Microbiol. 76:75-81. https://doi.org/10.1016/ S0168-1605(02)00002-8

Rantsiou K. and Cocolin L. 2006. New developments in the study of the microbiota of naturally fermented sausages as determined by molecular methods: a review. Int J Food Microbiol. 108:255267. https://doi.org/10.1016/j.ijfoodmicro.2005.11.013

Semjonovs P. and Zikmanis P. 2008. Evaluation of novel lactose-positive and exopolysaccharide-producing strain of Pediococcus pentosaceus for fermented foods. Eur Food Res Technol. 227(3):851-856. https://doi.org/10.1007/s00217-007-0796-4.

Skocińska K., Wójciak K. and Zielińska D. 2016. Probiotic microorganisms in dry fermented meat products. In: Rao V. and Rao L.G.(eds.), Probiotics and prebiotics in human nutrition and health. InTech., Croatia, pp. 279-300. https://doi.org/10.5772/64090

Søndergaard A.K. and Stahnke L.H. 2002. Growth and aroma production by Staphylococcus xylosus, S. carnosus and S. equorum - a comparative study in model systems. Int J Food Technol. 75(1-2):99-109. https://doi.org/10.1016/S01681605(01)00729-2

Stiles M.E. 1994. Bacteriocins produced by Leuconostoc species. J Diary Sci. 77(9):2718-2724. https://doi.org/10.3168/jds. S0022-0302(94)77214-3

Toldra F. 2002. Dry-cured meat products. Food \& Nutrition Press, Trumbull, CT. https://onlinelibrary.wiley.com/doi/ pdf/10.1002/9780470385111.fmatter

Tosukhowong A., Visessanguan W., Pumpuang L., Tepkasikul P., Panya A. and Valyasevi R. 2011. Biogenic amine formation in Nham, a Thai fermented sausage, and the reduction by commercial starter culture, Lactiplantibacillus plantarum BCC 9546. Food Chem. 129(3):846-853. https://doi.org/10.1016/j. foodchem.2011.05.033

Urso R., Comi G. and Cocolin L. 2006. Ecology of lactic acid bacteria in Italian fermented sausages: isolation, identification and molecular characterization. System Appl Microbiol. 29(8):671680. https://doi.org/10.1016/j.syapm.2006.01.012

Vasilev A., Aleksic B., Tarbuk A., Dimitrijevic M., Karabasil N., Cobanovic N., et al. 2015. Identification of lactic acid bacteria isolated from Serbian traditional fermented sausages Sremski and Lemeski kulen. Procedia Food Sci. 5:300-303. https://doi. org/10.1016/j.profoo.2015.09.071 
Versalovic J., Schneider M., de Brujin F. and Lupski J.R. 1994. Genomic fingerprinting of bacteria using repetitive sequence based PCR (rep-PCR). Methods Mol Biol. 5:25-40.

Veskovic-Moracanin S. 2010. Lactic acid bacteria bacteriocins as natural food protectors: possibilities of application in meat industry. Meat Technol. 51(1):83-94.
Zdolec N., Hadziosmanovic M., Kozacinski L., Cvrtila Z., Filipovic I., Skrivanko M. and Leskovar K. 2008. Microbial and physicochemical succession in fermented sausages produced with bacteriocinogenic culture of Lactobacillus sakei and semi-purified bacteriocin mesenterocin Y. Meat Sci. 80:480-487. https://doi. org/10.1016/j.meatsci.2008.01.012 